A C G

publications

Org. Commun. 11:2 (2018) 75-79

organic

communications

\title{
Towards 3-(2-adamantylidene)diamantane derivatives through the McMurry cross coupling reaction
}

\author{
Ngo Trung Hoc $\odot^{1,2, *}$, Vladimir N. Rodionov, $\oplus^{1}$ and Andrey A. Fokin $\odot^{1}$
}

\author{
${ }^{1}$ Igor Sikorsky Kiev Polytechnic Institute, pr. Pobedy 37, Kiev, 03056 Ukraine; \\ ${ }^{2}$ The Viet Nam University of Firefighting and Prevention, 243 Khuat duy tien, Hanoi 10000,
}

Vietnam

(Received March 19, 2018; Revised April 29, 2018; Accepted April 30, 2018)

\begin{abstract}
Diamondoid assemblies have a potential in nanoelectronics as the substrates for self-assembled monolayer formation. However, selective functionalization of such molecules is cumbersome. We demonstrate that the McMurry cross-coupling reaction is useful for the preparation of 3-(2-adamantylidene)diamantane derivatives with substituents at the tertiary and secondary positions of the diamantane moiety. This allows to create the surface attachment points in the diamondoid structure.
\end{abstract}

Keywords: Diamondoids; nanoelectronics; functionalization of diamondoids; Mc'Murry reaction. (C) 2018 ACG Publications. All rights reserved.

\section{Introduction}

Diamondoids (adamantane, diamantane, triamantane, and higher polymantanes) occur in natural petroleum deposits. In most crude oils diamondoid concentrations are in the order of 1-100 ppm and are presented predominantly by adamantane, diamantane and their alkyl derivatives [1]. Only adamantane, diamantane and triamantane exist as a single isomers, higher members of the series can exist in more than one isomeric form and the number of isomers increase with the growing size. Higher diamondoids have a potential as building blocks for nanoelectronic devices. It was shown that tetramantane thiol form well-ordered self-assembled monolayers (SAMs) on gold surface and material [2-6] thus obtained display monochromatic electron emission with low-kinetic energy threshold [3]. Besides, diamondoids and their derivatives serve as a model for hydrogen terminated diamond nanoparticles [7-10]. The availability of diamondoids up to hexamantanes (with $0.6 \mathrm{~nm}$ particle size) or pentamantanes (with $0.75 \mathrm{~nm}$ particle size) in preparative quantities from oil limited. The larger diamondoid particles are not available despite their potential applications in nanoelectronics [7-12]. This challenge may be addressed by coupling lower diamondoids with various spacers. While the $\mathrm{sp}^{3}-\mathrm{sp}^{3}$ diamondoid dimers [13] reproduce parts of the hydrogen-terminated diamond lattice, the $\mathrm{sp}^{2}$ dimers [9] is a model for the presence of unsaturation in diamondoids. This may allow fine tuning the electronic properties of diamond-based materials. The C-H-bond functionalizations of diamondoid oligomers were performed, these provided halogen and hydroxy derivatives with conservation of unsaturation, but with low selectivities[9]. Various alkenes have been produced by the McMurry ketone coupling reaction as a powerful synthetic method [14-16].

\footnotetext{
* Corresponding author: E-Mail: trunghoct34@gmail.com
} 
In present study we develop the new synthetic route to the 3-(2-adamantylidene)diamantane derivatives utilizing the McMurry cross-coupling reaction where one of the components already contains the substituent in a certain position of the diamantane cage.

\section{Results and Discussion}

Hydroxyketal (1) was used as a starting compound, whose hydrolyses in the mixture of $10 \%$ $\mathrm{H}_{2} \mathrm{SO}_{4}$ aqueous-THF solution allows to prepare 10-hydroxy-3-diamantanone (2) [17]. After the hydroxy-group protection through the reaction with trimethylsilyl chloride 10-trimethysiloxane-3diamantanone (3) [18] was obtained. The later was used as a starting compound for the synthesis of 10-trimethylsiloxane - 3-(2-adamantylidene)diamantane (4) through the McMurry cross-coupling with 2 -adamantanone under argon atmosphere by adding the mixture of ketones to a freshly prepared titanium reagent (Scheme 1).

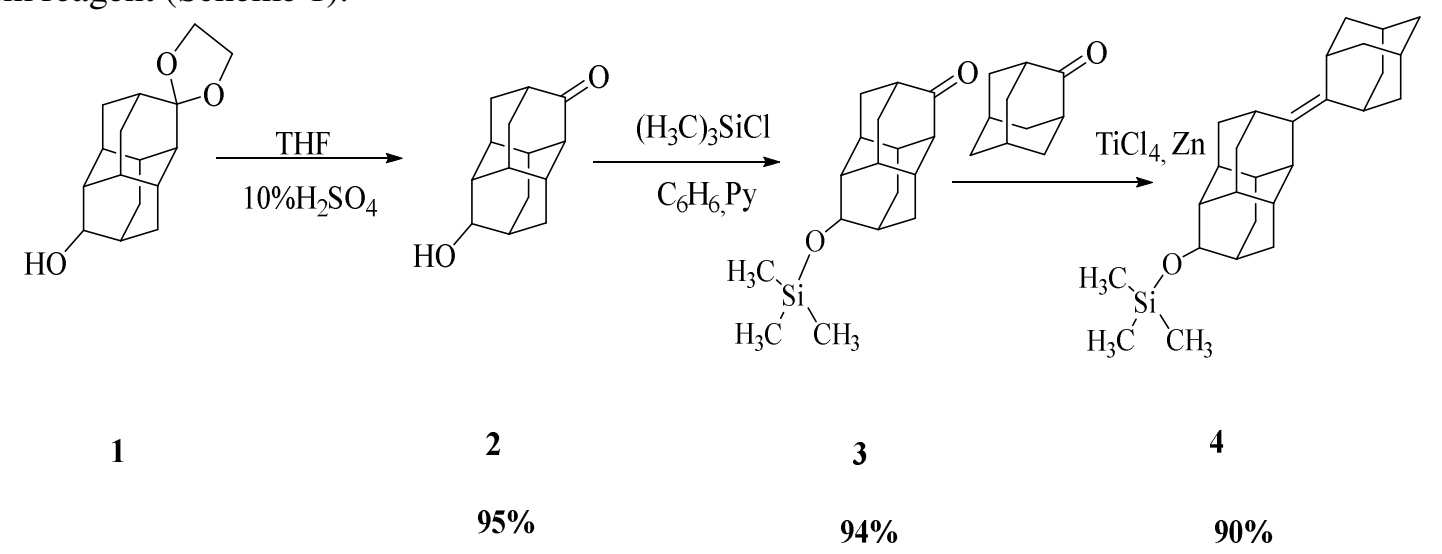

Scheme 1. Synthesis of 10-trimethylsiloxane - 3-(2-adamantylidene) diamantine (4)

In a similar way, 9-hydroxy-3-diamantanone (5) [19] was used as a starting material for the synthesis of 9-trimethylsiloxane - 3-(2-adamantylidene)diamantane (7). After silylation of (5) to give (6), the McMurry coupling as above gave (7) in $92 \%$ yield.



Scheme 2. Synthesis of 9-trimethylsiloxane - 3-(2-adamantylidene) diamantane (7)

\section{Experimental}

\subsection{Chemical Material and Apparatus}

All reagents and solvents employed were purified and dried or used without further purification as purchased from Fluka, Sigma-Aldrich, and Merck. Elemental analysis were recorded on the VARIO EL III elemental analyzer instrument for $\mathrm{C}, \mathrm{H}$, and N. ${ }^{1} \mathrm{H},{ }^{13} \mathrm{C}-\mathrm{NMR}$ spectra were recorded on a Bruker DPX-400 spectrometer operating at $400.13 \mathrm{MHz}$ for ${ }^{1} \mathrm{H}$ and $100.61 \mathrm{MHz}$ for ${ }^{13} \mathrm{C}$, solvent $\mathrm{CDCl}_{3}$. 
Column chromatography performed on silica gel $60(0.063-0.200 \mathrm{~mm})$, purchased from Merck (Darmstadt, Germany). The GLC analysis performed on a capillary column Optima-1 on Shimadzu GC-14B equipped with a flame-ionization detector.

\subsection{0-Hydroxy-3-diamantanone (2)}

To a solution of $2 \mathrm{~g}$ (76 mmol) of ketal (1) in $10 \mathrm{~mL}$ of THF $100 \mathrm{~mL}$ of $10 \%$ solution of sulfuric acid was added, the mixture was maintained at stirring without heating for 5 hours. Excess sulfuric acid was neutralized with solid sodium hydroxide till $\mathrm{pH} 7-8$, the reaction product was extracted with dichloromethane, the extract was dried with $\mathrm{Na}_{2} \mathrm{SO}_{4}$ and the solvent was distilled off in a vacuum.

Yield $1.57 \mathrm{~g}(95 \%), \mathrm{mp} .158^{\circ} \mathrm{C}$ (hexane). ${ }^{1} \mathrm{H}$ NMR spectrum, $\delta$, ppm: $1.46-1.52 \mathrm{~s}(1 \mathrm{H}, \mathrm{CH})$, $1.61-1.75 \mathrm{~m}\left(8 \mathrm{H}, \mathrm{CH}, \mathrm{CH}_{2}\right), 1.83-1.93 \mathrm{~m}\left(5 \mathrm{H}, \mathrm{CH}, \mathrm{CH}_{2}\right), 2.0-2.08 \mathrm{~m}\left(3 \mathrm{H}, \mathrm{CH}, \mathrm{CH}_{2}\right), 3.77 \mathrm{~s}(1 \mathrm{H}$, $\mathrm{OH}) .{ }^{13} \mathrm{C}$ NMR spectrum, $\delta$, ppm: $\left.\left.30.1\left(\mathrm{CH}_{2}\right), 31.2(\mathrm{CH}), 32.3 \mathrm{CH}_{2}\right), 33.8 \mathrm{CH}_{2}\right), 34.3(\mathrm{CH}), 34.5$ $(\mathrm{CH})$, 34.6 $\left(\mathrm{CH}_{2}\right), 36.1\left(\mathrm{CH}_{2}\right), 41.3\left(\mathrm{CH}_{2}\right), 44.6\left(\mathrm{CH}_{2}\right), 74.5(\mathrm{COH}), 217.2(\mathrm{C}=\mathrm{O})$. Found \% $\mathrm{C} 77.03$, $\mathrm{H}$ 8.31. $\mathrm{C}_{14} \mathrm{H}_{18} \mathrm{O}_{2}$. Calculated \% C 77.05, H 8.30.

\subsection{0-Trimethysiloxane-3-diamantanone (3)}

In a $250 \mathrm{~mL}$ vessel equipped with a mechanical stirrer and a reflux condenser, $150 \mathrm{~mL}$ of benzene and $5 \mathrm{~mL}(31.4 \mathrm{mmol})$ trimethylsilane chloride are placed, then a mixture of $2 \mathrm{~g}$ (9.17 mmol) 10 hydroxydiamantan-3-one in $10 \mathrm{~mL}$ of pyridine added dropwise and the heating temperature rises to 80 $-85^{\circ} \mathrm{C}$ for 2 hours. The benzene layer is separated, washed with $100 \mathrm{~mL}$ of distilled water, twice with $100 \mathrm{~mL}$ of $5 \% \mathrm{HCl}$ solution and $100 \mathrm{~mL}$ of saturated $\mathrm{NaCl}$ solution. The organic layer was dried over anhydrous $\mathrm{Na}_{2} \mathrm{SO}_{4}$, the solvent was evaporated on a vacuum rotary evaporator to constant weight, the residue was purified by column chromatography over silica gel, eluent-hexane /diethyl ether 20/1.

Yield $2.5 \mathrm{~g}(94 \%), \mathrm{mp} .74^{\circ} \mathrm{C}$ (hexane). ${ }^{1} \mathrm{H}$ NMR spectrum, $\delta$, ppm: $0.09 \mathrm{~s}\left(9 \mathrm{H}, \mathrm{CH}_{3}\right), 1.37-1.45$ $\mathrm{m}(1 \mathrm{H}, \mathrm{CH}), 1.7-1.98 \mathrm{~m}\left(11 \mathrm{H}, \mathrm{CH}, \mathrm{CH}_{2}\right), 2.14 \mathrm{~s}(1 \mathrm{H}, \mathrm{CH}), 2.38 \mathrm{~s}(2 \mathrm{H}, \mathrm{CH}), 2.42 \mathrm{~m}(1 \mathrm{H}, \mathrm{CH}), 3.83 \mathrm{~s}$ $(1 \mathrm{H}, \mathrm{CH}) .{ }^{13} \mathrm{C}$ NMR spectrum, $\delta$, ppm: $0.23(\mathrm{TMS}), 30.2\left(\mathrm{CH}_{2}\right), 30.4(\mathrm{CH}), 32.3(\mathrm{CH}), 34.6\left(\mathrm{CH}_{2}\right)$, $35.7(\mathrm{CH}), 37.6\left(\mathrm{CH}_{2}\right), 38.1\left(\mathrm{CH}_{2}\right), 38.2(\mathrm{CH}), 39.0(\mathrm{CH}), 43.1(\mathrm{CH}), 44.3(\mathrm{CH}), 55.6(\mathrm{CH}), 74.3(\mathrm{C}-$ OTMS), $217.5(\mathrm{C}=\mathrm{O})$. Calculated for $\mathrm{C}_{17} \mathrm{H}_{26} \mathrm{O}_{2} \mathrm{Si} ; \% \mathrm{C} 70.29, \mathrm{H}$ 9.02. Found, \% C 70.26, H 9.03.

\subsection{0-Trimethylsiloxane - 3-(2-Adamantylidene) diamantine (4)}

In a $100 \mathrm{~mL}$ 2-necked reactor equipped with a magnetic stirrer, septum and an efficient reflux condenser with a device for supplying argon with a bubble counter, $60 \mathrm{~mL}$ of THF distilled over sodium in an argon stream was loaded with a syringe. The reactor is cooled with ice water and a 3.75 $\mathrm{mL}(34 \mathrm{mmol}) \mathrm{TiCl}_{4}$ solution is slowly fed through the septum. The vortex of argon is increased and $4.5 \mathrm{~g}(70.3 \mathrm{mmol})$ of zinc dust with intensive mixing is filled with a funnel through the open mouth of the reactor. The reactor is carefully insulated from the external environment, under argon atmosphere and the reaction mixture is boiled for 1 hour with continuous intensive stirring. The reaction mixture is cooled to room temperature and sequentially loaded with a syringe of $1 \mathrm{~mL}$ of dry pyridine, $2 \mathrm{~g}$ (13

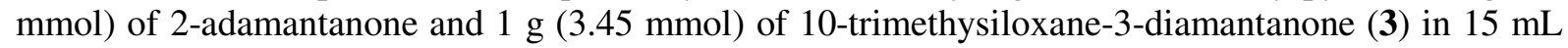
of THF, distilled over sodium in the current of argon. The reaction mixture was stirred continuously for 20-24 hours in an argon atmosphere, cooled to room temperature, and slowly poured out with vigorous stirring and cooled with ice water to a flat bottom flask, in which $120 \mathrm{~mL}$ of a $10 \%$ solution of $\mathrm{K}_{2} \mathrm{CO}_{3}$ were pre-placed. The viscous mass of the resulting dark blue color is stirred for 15 minutes with $200 \mathrm{~mL}$ of benzene, then filtered in a Buchner well, and the precipitate was washed three times with $50 \mathrm{~mL}$ of benzene on the filter. The benzene layer was separated, washed with $100 \mathrm{~mL}$ of distilled water, twice with $100 \mathrm{~mL}$ of a $5 \%$ solution of $\mathrm{HCl}$ and $100 \mathrm{~mL}$ of saturated $\mathrm{NaCl}$ solution. The organic layer was dried over anhydrous $\mathrm{Na}_{2} \mathrm{SO}_{4}$, the solvent is evaporated on a vacuum rotary evaporator to a constant mass, the residue was purified by column chromatography on silica gel, eluent hexane.

Yield $1.26 \mathrm{~g}(90 \%)$, mp. $124{ }^{\circ} \mathrm{C}$ (hexane). ${ }^{1} \mathrm{H}$ NMR spectrum, $\delta$, ppm: $0.12 \mathrm{~s}\left(9 \mathrm{H}, \mathrm{CH}_{3}\right), 1.2-$ $1.26 \mathrm{~m}(3 \mathrm{H}, \mathrm{CH}), 1.53 \mathrm{~s}(1 \mathrm{H}, \mathrm{CH}), 1.6-1.95 \mathrm{~m}\left(23 \mathrm{H}, \mathrm{CH}, \mathrm{CH}_{2}\right), 2.65 \mathrm{~s}(1 \mathrm{H}, \mathrm{CH}), 2.79 \mathrm{~s}(1 \mathrm{H}, \mathrm{CH})$, $2.90 \mathrm{~s}(2 \mathrm{H}, \mathrm{CH}) .{ }^{13} \mathrm{C}$ NMR spectrum, $\delta$, ppm: $2.9\left(\mathrm{CH}_{3}\right), 28.5(\mathrm{CH}), 29.0(\mathrm{CH}), 29.7\left(\mathrm{CH}_{2}\right), 31.9(\mathrm{CH})$, $32.2(\mathrm{CH}), 36.5(\mathrm{CH}), 37.3\left(\mathrm{CH}_{2}\right), 38.7\left(\mathrm{CH}_{2}\right), 39.5(\mathrm{CH}), 39.6\left(\mathrm{CH}_{2}\right), 39.7\left(\mathrm{CH}_{2}\right), 40.2(\mathrm{CH}), 41.8$ 
$(\mathrm{CH}), 46.1\left(\mathrm{CH}_{2}\right), 46.2\left(\mathrm{CH}_{2}\right), 70.6(\mathrm{C}-\mathrm{OTMS}), 132.4-134.2(\mathrm{C}=\mathrm{C})$. Found \% C 79.35, H 9.87, $\mathrm{C}_{27} \mathrm{H}_{40} \mathrm{OSi}$. Calculated \% C 79.32, H 9.91.

9-Trimethysiloxane-3-diamantanone (6): Mp. $78^{\circ} \mathrm{C}$ (hexane). ${ }^{1} \mathrm{H}$ NMR spectrum, $\delta$, ppm: $0.09 \mathrm{~s}(9 \mathrm{H}$, $\left.\mathrm{CH}_{3}\right), 1.57-1.65 \mathrm{~m}(2 \mathrm{H}, \mathrm{CH}), 1.68-1.9 \mathrm{~m}\left(10 \mathrm{H}, \mathrm{CH}, \mathrm{CH}_{2}\right), 2.04 \mathrm{~s}(1 \mathrm{H}, \mathrm{CH}), 2.18 \mathrm{~s}(2 \mathrm{H}, \mathrm{CH}), 2.3 \mathrm{~m}$ $(2 \mathrm{H}, \mathrm{CH}) .{ }^{13} \mathrm{C}$ NMR spectrum, $\delta$, ppm: $3.07(\mathrm{TMS}), 35.4(\mathrm{CH}), 37.5(\mathrm{CH}), 38.8\left(\mathrm{CH}_{2}\right), 42.4(\mathrm{CH})$, $43.4(\mathrm{CH}), 44.7\left(\mathrm{CH}_{2}\right), 45.2\left(\mathrm{CH}_{2}\right), 54.5(\mathrm{CH}), 69.6(\mathrm{C}-\mathrm{OTMS}), 217.5(\mathrm{C}=\mathrm{O})$. Calculated for $\mathrm{C}_{17} \mathrm{H}_{26} \mathrm{O}_{2} \mathrm{Si}$ : \% C 70.29, H 9.02. Found \% C 70.34, H 9.03.

9-Trimethylsiloxane - 3-(2-Adamantylidene) diamantine (7): $\mathrm{Mp} .170^{\circ} \mathrm{C}$ (hexane). ${ }^{1} \mathrm{H}$ NMR spectrum, $\delta$, ppm: $0.14 \mathrm{~s}\left(9 \mathrm{H}, \mathrm{CH}_{3}\right), 1.64-1.7 \mathrm{~m}\left(6 \mathrm{H}, \mathrm{CH}, \mathrm{CH}_{2}\right), 1.71-1.8 \mathrm{~m}\left(9 \mathrm{H}, \mathrm{CH}, \mathrm{CH}_{2}\right), 1.8-$ $1.9 \mathrm{~m}\left(9 \mathrm{H}, \mathrm{CH}, \mathrm{CH}_{2}\right), 1.891-2.0 \mathrm{~m}\left(3 \mathrm{H}, \mathrm{CH}, \mathrm{CH}_{2}\right), 2.65 \mathrm{~s}(1 \mathrm{H}, \mathrm{CH}), 2.82 \mathrm{~s}(1 \mathrm{H}, \mathrm{CH}), 2.92 \mathrm{~s}(2 \mathrm{H}$, $\mathrm{CH}) .{ }^{13} \mathrm{C}$ NMR spectrum, $\delta$, ppm: $2.94\left(\mathrm{CH}_{3}\right), 28.6(\mathrm{CH}), 29.1(\mathrm{CH}), 29.7(\mathrm{CH}), 31.9(\mathrm{CH}), 32.3(\mathrm{CH})$, $36.6(\mathrm{CH}), 37.3\left(\mathrm{CH}_{2}\right), 38.7\left(\mathrm{CH}_{2}\right), 39.5(\mathrm{CH}), 39.6\left(\mathrm{CH}_{2}\right), 39.7\left(\mathrm{CH}_{2}\right), 40.3(\mathrm{CH}), 41.8(\mathrm{CH}), 46.1$ $\left(\mathrm{CH}_{2}\right), 46.2\left(\mathrm{CH}_{2}\right), 70.5$ (C-OTMS), $132.4-134.2(\mathrm{C}=\mathrm{C})$. Found \% C 79.35, $\mathrm{H}$ 9.87. $\mathrm{C}_{27} \mathrm{H}_{40} \mathrm{OSi}$. Calculated \% C 79.37, H 9.83.

\section{Conclusion}

We show that the involvement of substituted diamondoidyl ketones into the McMurry cross coupling reaction allow the preparation of functionalized 3-(2-adamantylidene)diamantanes. Such substituted diamondoid dimers with $\mathrm{sp}^{2}$ "defects" seem as building blocks for the preparation of respective thiols as surface modifiers with potential in diamond nanoelectronics.

\section{Supporting Information}

Supporting information accompanies this paper on http://www.acgpubs.org/OC

\section{ORCID}

Ngo Trung Hoc : $0000-0001-6571-8345$

Andrey A. Fokin: 0000-0002-6381-8948

Vladimir N. Rodionov: 0000-0002-8282-6126

\section{Acknowledgements}

The authors thank Justus Liebig University of Giessen (Giessen, Germany) for NMR facilities.

\section{References}

[1] Dahl, J. E. P. Moldowan, J. M. Peters, K. E. Claypool, G. E. Rooney, M. A. Michael, G. E. Mello, M. R. Kohnen, M. L. Diamondoid hydrocarbons as indicators of natural oil cracking. Nature 1999, 399, 54 - 57. doi:10.1038/19953

[2] Willey, T. M.; Fabbri, J. D.; Lee, J. R. I.; Schreiner, P. R.; Fokin, A. A.; Fokina, N. A; Dahl, J. E. P.; Carlson, R. M. K.; Vance, A. L.; Yang, W.; Terminello, L. J.; van Buuren, T.; Melosh, N. A. Near-edge Xray absorption fine structure spectroscopy of diamondoid thiol monolayers on gold. J. Am. Chem. Soc. 2008, 130, 10536. DOI: 10.1021/ja711131e

[3] Yang, W. L.; Fabbri J. D.; Willey, T. M.; Lee, J. R. I.; Dahl, J. E.; Carlson, R. M. K.; Schreiner, P. R.; Fokin, A. A.; Tkachenko, B. A.; Fokina, N. A.; Meevasana, W.; Mannella, N.; Tanaka, K.; Zhou, X. J.; van Buuren, T.; Kelly, M. A.; Hussain, Z.; Melosh, N. A.; Shen, Z.-X. Monochromatic electron photoemission from diamondoid monolayers. Science 2007, 316, 1460. DOI: 10.1126/science.1141811

[4] Roth, S.; Leuenberger, D.; Osterwalder, J.; Tkachenko, B. A.; Dahl, J. E. P.; Carlson, R. M. K.; Fokin, A. A.; Schreiner, P. R.; Hengsberger, M. Negative-electron-affinity diamondoid monolayers as high-brilliance 
source for ultrashort electron pulses. Chem. Phys. Lett. 2010, 495, 102. https://doi.org/10.1016/j.cplett.2010.06.063

[5] Thimmavajjula, K. Ge, C. Fabbri, J. Clay, W. Tkachenko, B. Fokin, A. Schreiner, P. Dahl, J.Carlson, R. Shen, Z.-X. Melosh, N. Ultra-low effective work function surfaces using diamondoid monolayers. Nature Nanotech. 2016, 11, 267-273. doi:10.1038/nnano.2015.277

[6] Clay, W. A.; Maldonado, J. R.; Pianetta, P.; Dahl, J. E. P.; Carlson, R. M. K.; Schreiner, P. R.; Fokin, A. A.;Tkachenko, B. A.; Melosh, N.; Shen, Z.-X. Photocathode device using diamondoid and cesium bromide films Appl. Phys. Lett. 2012, 101, 241605. https://doi.org/10.1063/1.4769043

[7] Fokin, A. A.; Tkachenko, B. A.; Gunchenko, P. A.; Gusev, D. V.; Schreiner. P. R. Functionalized Nanodiamonds Part I. An experimental assessment of diamantane and computational predictions for higher diamondoids Chem. Eur. J. 2005, 11, 7091. https://doi.org/10.1002/chem.200500031

[8] Fokin, A. A.; Zhuk, T. S.; Pashenko, A. E.; Dral, P. O.; Gunchenko, P. A.; Dahl, J. E. P.; Carlson, R. M. K.; Koso, T. V.; Serafin, M.; Schreiner, P. R.Oxygen-doped nanodiamonds: Synthesis and functionalizations. Org. Lett. 2009, 11, 3068. DOI: 10.1021/o1901089h

[9] Zhuk, T.S.; Koso, T.; Pashenko, A.E.; Trung Hoc, N.; Rodionov, V.N.; Serafin, M.; Schreiner, P.R.; Fokin, A.A. Toward an Understanding of Diamond $\mathrm{sp}^{2}$-Defects with Unsaturated Diamondoid Oligomer Models. $J$. Am. Chem. Soc. 2015, 137, 6577-6586, doi:10.1021/jacs.5b01555.

[10] Fokin, A. A.; Zhuk, T. S.; Pashenko, A. E., et. al. Functionalization of Homodiamantane: Oxygen insertion reactions without rearrangement with dimethyldioxirane J. Org. Chem. 2014, 79, 1861. DOI: $10.1021 /$ jo4026594

[11] Fokin, A.A.; Yurchenko, R.I.; Tkachenko, B.A.; Fokina, N. A.; Gunawan, M. A.; Poinsot, D.; Dahl, J. E. P.; Carlson, R. M. K.;Serafin, M.; Cattey, H.; Hierso, J.-C.; Schreiner, P. R. Selective preparation of diamondoid phosphonates. J. Org. Chem. 2014, 79, 5369-5373.

[12] Banerjee, S.; Saalfrank, P. Vibrationally resolved absorption, emission and resonance Raman spectra of diamondoids: a study based on time-dependent correlation functions. Phys. Chem. Chem. Phys. 2014, 16, 144-158. DOI: $10.1039 /$ C3CP53535E

[13] Fokin, A. A.; Chernish, L. V.; Gunchenko, P. A.; Tikhonchuk, E. Y.; Hausmann, H.; Serafin, M.; Dahl, J. E. P.; Carlson, R. M. K.; Schreiner, P. R. Stable alkanes containing very long carbon-carbon bonds J. Am. Chem. Soc. 2012, 134, 13641-13650. DOI:10.1021/ja302258q

[14] McMurry, J. E.; Felming, M .P. New method for the reductive coupling of carbonyls to olefins. Synthesis of. beta.-carotene. J. Am. Chem. Soc. 1974, 96, 4708-4709, doi:10.1021/ja00821a076.

[15] M M Krayushkin, M A Kalik, V A Migin. McMurry reaction in the synthesis of photochromic dihetarylethenes.Russ.Chem.Rev.2009,78 329. https://doi.org/10.1070/RC2009v078n04ABEH004018

[16] Tanpure, R.P., Harkrider, A.R., Strecker, T.E., Hamel, E., Trawick, M.L., and Pinney, K.G. Application of the McMurry Coupling Reaction in the Synthesis of Tri- and Tetra-arylethylene Analogues as Potential Cancer Chemotherapeutic Agents. Bioorg. Med. Chem. 2009, 17, 6993-7001. DOI :10.1016/j.bmc.2009.08.011

[17] Ngo Trung Hoc; Fokin, A.A.; Rodionov, V.N Synthesis of 10-methoxydiamantan-3-one. Molbank. 2018. 2018, M990; doi:10.3390/M990

[18] T. Morita, S. Yoshida, Y. Okamoto, H. Sakurai,Chlorotrimethysilane/Sodium iodide : A new reagent for conversion of ancohols into iodides Synthesis, 1979, 379. DOI: 10.1055/s-1979-28689

[19] Hoc, N.T.; Kusko, A.O.; Fokin, A.A.; Rodionov, V.N. Functional derivatives of diamantanone. Russ. J. Org. Chem. 2016, 52, 1209-1211, doi:10.1134/S1070428016080212.

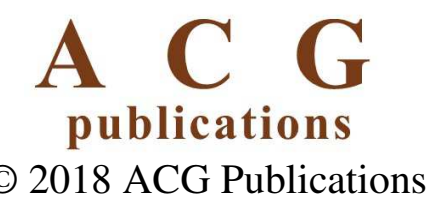

